\title{
Improving almond crop forecasts
}

\author{
Jeffrey Dorfman $\square$ Dale Heien
}

\section{Wide fluctuations in the California almond crop from year to year complicate marketing strategy. Including early-season weather data could improve the accuracy of crop estimates.}

\begin{abstract}
$T_{\text {he }}$ he California almond crop fluctuates widely: over the last 10 years it has ranged from 181 to 587 million meat pounds (the weight of the kernels only, excluding the shells) (fig. 1). Such fluctuations make planning a marketing strategy very difficult. In this article, we report on our attempt to use weather information to improve the annual California almond crop forecast.

There are essentially two markets for almonds: one for processing use in cereals, chocolate bars, and the like, and another for direct consumption as raw or smoked nuts. Another dimension is added by export demand, mainly from West Germany, where almonds are used in processing. Because demand by these processors is relatively stable from year to year and the crop varies to such an extent, almond sellers must have a large "swing" market of customers who are flexible in adapting their demand to changing market conditions, especially price. Almond
\end{abstract}

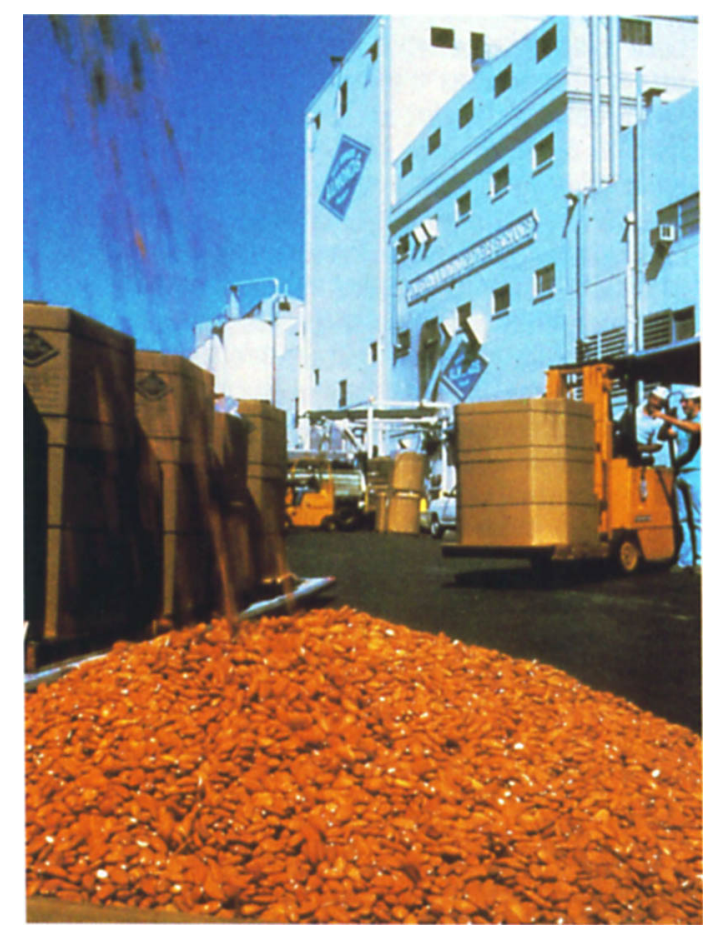

California's almond crop ranges from 181 to 587 million pounds of nut meats per year; demand is relatively stable. egies with these factors in mind.

Although almonds can be stored, it is generally desirable to sell all, or almost all, of a given year's crop. In large crop years, some stocks may be held over, but a marketer still must decide what price is needed to sell the desired amount. Almond marketers not only must select a pricing strategy that will clear the market, but also must accurately forecast what that market (harvest) will be. For this they rely on state crop estimates. If these estimates are incorrect, both the marketers and the producers will lose potential profit. Both would benefit from having an early, accurate estimate of the almond crop size.

\section{Model development}

Each year the California Crop and Livestock Reporting Service estimates the California almond crop (hereafter referred to as the state estimate). While generally quite good, occasionally the estimate is off by a significant amount from a marketing viewpoint. It takes into account the bearing acreage, a sample of the number of nuts per tree, and various scientific analyses of a large number of sampled nuts. The final state sample is taken in June and the final estimate is released in mid-July. The harvest generally starts in early August, peaks in September, and continues through November or even December. Because of the long harvest season, marketers have to wait months to know the true crop size.

Our goal was to produce an improved early estimate of the California almond crop. Although it seemed unlikely that the state's technical analyses could be improved, the forecasting errors suggested that something might be missing from the model. We began our search with the weather.

A plant needs water, sunlight, and nutrients for growth. Despite the need for water, hard rain during the bloom period can interfere with cross-pollination and severely shrink crop size. The state sample picks up such early-season rain damage, however, so we did not choose rainfall as a weather variable. marketers must design their pricing strat-
Temperature could be considered a fourth class of input. While it is clear that extreme temperatures, both cold and hot, can damage plants, the effects of moderate temperatures are not completely understood. We therefore chose temperature as the weather variable. Temperature also could be used as a proxy for soil moisture because of the proportional relationship between temperature and evapotranspiration.

The next question was how to measure temperature for a crop grown over a large part of the state. The California $\mathrm{Al}-$ mond Growers Exchange (CAGE) provided production records for 10 years (1976-85). Using their data, and treating each locale as typical of the weather throughout the area from which the almonds were gathered, we derived weights for the different almond-growing areas of the state. Next we obtained temperature data for these locales. Finally, computation of a weighted average of the data provided a single value for the entire state. In extending this analysis to other crops, county acreages of bearing orchards could be used to construct the weights.

Two alternative statistics were computed from temperature data. The first was cooling degree days per month. (Cooling degree days are compiled to estimate energy use for air-conditioning in the summer.) One cooling degree day was added for each degree that the daily mean temperature exceeded $65^{\circ} \mathrm{F}$. A day with a mean temperature of $70^{\circ}$ would be a 5 cooling degree day. Nothing was subtracted for days with average temperatures below $65^{\circ}$. Each day's value is simply added over the month. The second statistic computed was the number of days in a month with a high temperature over $90^{\circ} \mathrm{F}$. Both statistics were compiled for the months of May, June, and July 197685 from National Oceanic and Atmospheric Administration data.

Discussions with Stephen Heinrichs and Melody Warfield at CAGE and University of California pomologists Dale Kester and Warren Micke, at Davis, led to the hypothesis that temperatures during May, June, and July should affect the size of the crop. There was no definite idea of what mathematical form the relationship between temperature and crop size would take. We then specified crop size relations using alternative mathematical forms and estimated these relations by regression techniques. We chose the state esti- 


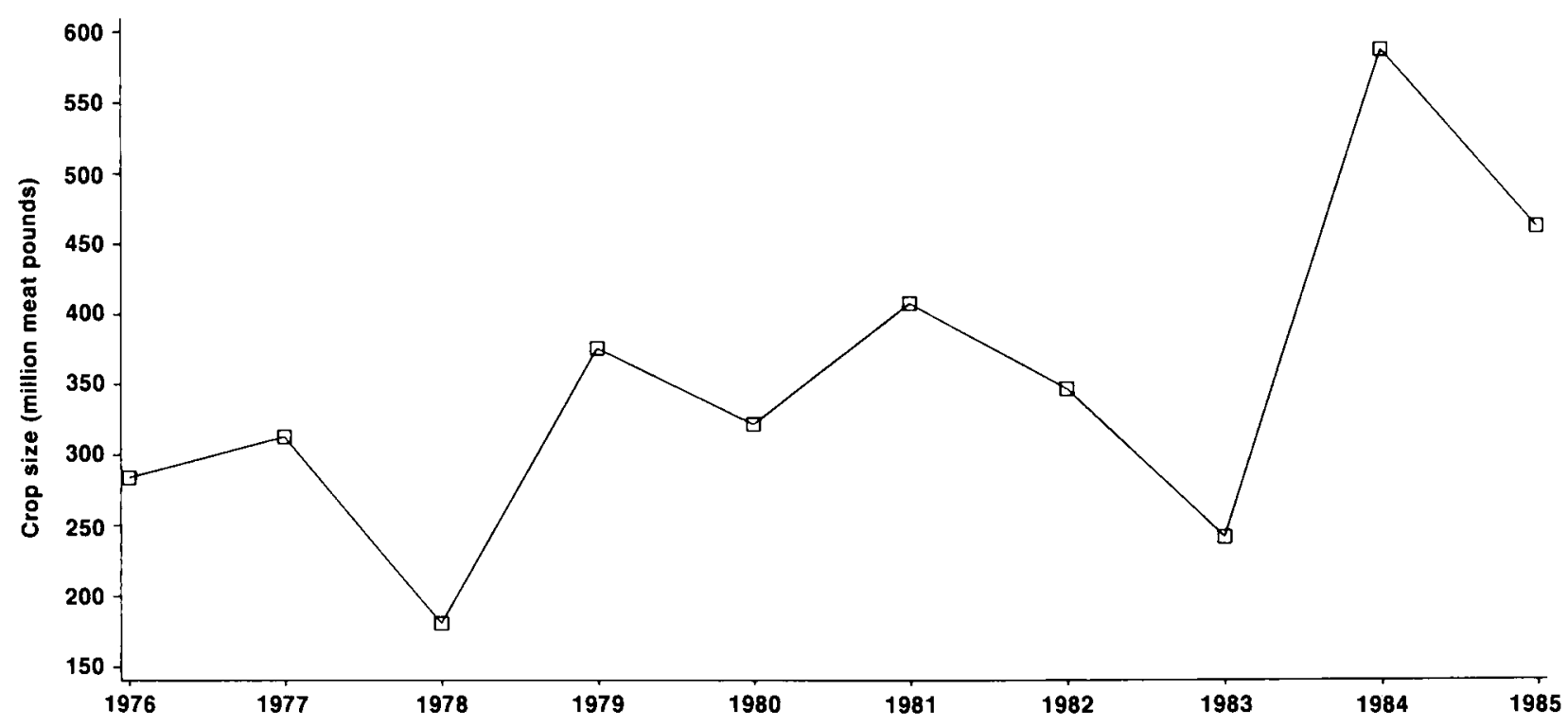

Fig. 1. California almond crop, 1976-85.

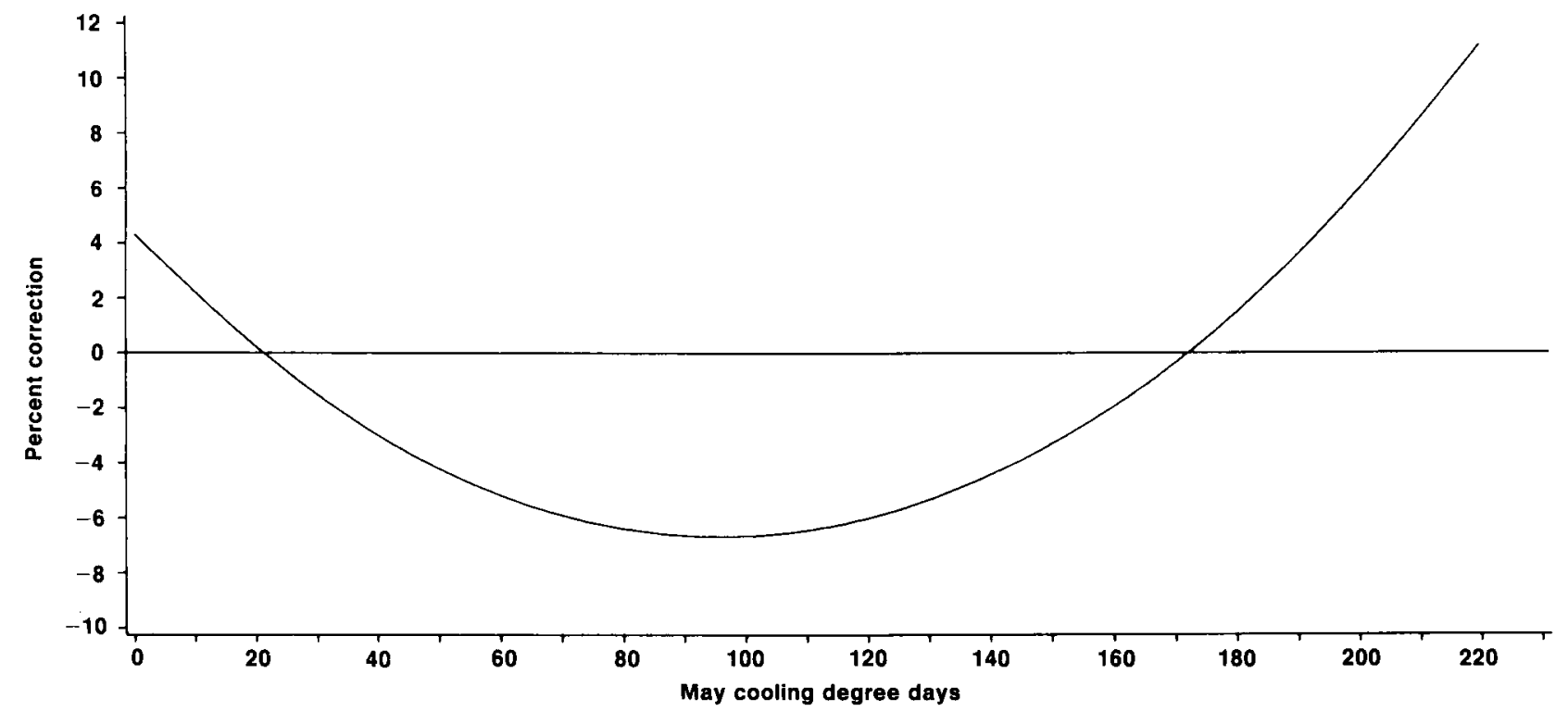

Fig. 2. Adjustment of the state forecast by the weather model shows the state estimate works well at around 21 and 172 cooling degree days but

tends to overestimate the crop between these two values and to underestimate it above 172.

mate as one explanatory variable to account for the acreage, nut density, and physical characteristics that the state sample measures. Then we added various combinations of weather variables, trying all three months (May, June, and July), with cooling degree days, cooling degree days squared, days over $90^{\circ}$, and days over $90^{\circ}$ squared as explanatory variables.

\section{Results}

It had seemed likely that the state estimate might be improved by adjusting for weather that occurred after the state took its sample. The results, however, showed that using June and July weather did not significantly improve the predictions, while inclusion of May temperatures con- siderably enhanced the models' performance.

Early-season weather has not been sufficiently studied in almonds, apparently because it was assumed that the state samples would show its effects. May is a crucial time for almond growth. If temperatures are warm then, the nuts will be bigger when the state takes its samples in June. But the state does not sample the nutrient reserve of the tree. The weather in May affects the whole tree, not just the nut; in good weather the tree stores extra energy in the form of carbohydrates. This will allow the almonds to grow more later in the season, resulting in larger kernels than projected by the state's sample. This "lagged" effect of the May temperatures seems to be missed, or improperly ac- counted for, in the state model. Including this effect enabled the almond crop to be predicted more accurately over the 10year period.

One of the models in particular provided good results. This model uses the ratio of the actual crop to the state estimate as the dependent variable. That is, the model predicts what multiple of the state estimate the actual crop will be. This cuts down on the variation in the dependent variable. The explanatory variables used were May cooling degree days and May cooling degree days squared. To obtain an estimate of a given year's crop, one multiplies the predicted ratio by the year's state estimate. The $\mathbf{R}^{2}$ shown (table 1 footnote) has been converted to reflect the model's explanation of the variation 
in crop size, not the variation in the ratio of the crop size to the state estimate.

The results of the model show the effect of the May weather. The signs and size of the two weather coefficients indicate that the weather correction is largest (in a negative direction) for a value of 97 cooling degree days, weather that is below average (since May weather averages about 130 cooling degree days). During the 10 years studied, May temperatures varied from a minimum of 15 cooling degree days in 1977 to a maximum of 220 cooling degree days in 1984. In years when the weather is particularly warm (over 172 cooling degree days), the correction is a positive one. Because of the parabolic form of the correction, the state estimate is unbiased for May cooling degree values of 21 and 172 . At these values, the weather adjustment model would give exactly the same estimate as the state model. The state model therefore will work well in a range around these two cooling degree day values, will be biased toward overestimation in between, and will be biased toward underestimation for values of more than 172 cooling degree days (fig. 2).

The correction improves the crop forecasts noticeably. For the past four years, this model has been within 1 percent of the actual crop (table 1).

\begin{tabular}{cccc}
\multicolumn{4}{c}{ TABLE 1. Model results } \\
\hline \hline Year & $\begin{array}{c}\text { Actual } \\
\text { crop }\end{array}$ & $\begin{array}{c}\text { State } \\
\text { estimate }\end{array}$ & $\begin{array}{c}\text { Weather } \\
\text { model }\end{array}$ \\
\hline \multicolumn{4}{c}{---meat pounds (millions)---- } \\
1976 & 284 & 280 & 266.4 \\
1977 & 313 & 310 & 313.2 \\
1978 & 181 & 205 & 194.9 \\
1979 & 376 & 350 & 347.9 \\
1980 & 322 & 340 & 318.6 \\
1981 & 408 & 450 & 437.9 \\
1982 & 347 & 365 & 348.9 \\
1983 & 242 & 250 & 242.6 \\
1984 & 587 & 520 & 592.1 \\
1985 & 462 & 495 & 462.1
\end{tabular}

NOTE: The model is as follows:

$Y=1.0431-0.0022722 X+0.00001175 X^{2}$

$$
\begin{array}{lll}
(16.82) & (-2.28) \quad(2.95)
\end{array}
$$$$
\text { MSE }=0.002792 \quad R^{2}=98.1 \% \quad n=10
$$

$Y=$ actual crop/state estimate

$X=$ May cooling degree days

The numbers in parentheses are the t-ratios.

\section{Conclusions}

The model developed here predicts the almond crop more accurately than does the state estimate. Because it is based on a correction of the state estimate for May weather, it can be computed immediately following the state estimate in July. The state estimate is by no means obsolete, however, since it forms the basis for this model.

Jeffrey Dorfman is a student and Dale $M$. Heien is Associate Professor in the Department of Agricul tural Economics, University of California, Davis The authors wish to acknowledge the help of the Callfornia Almond Growers Exchange.
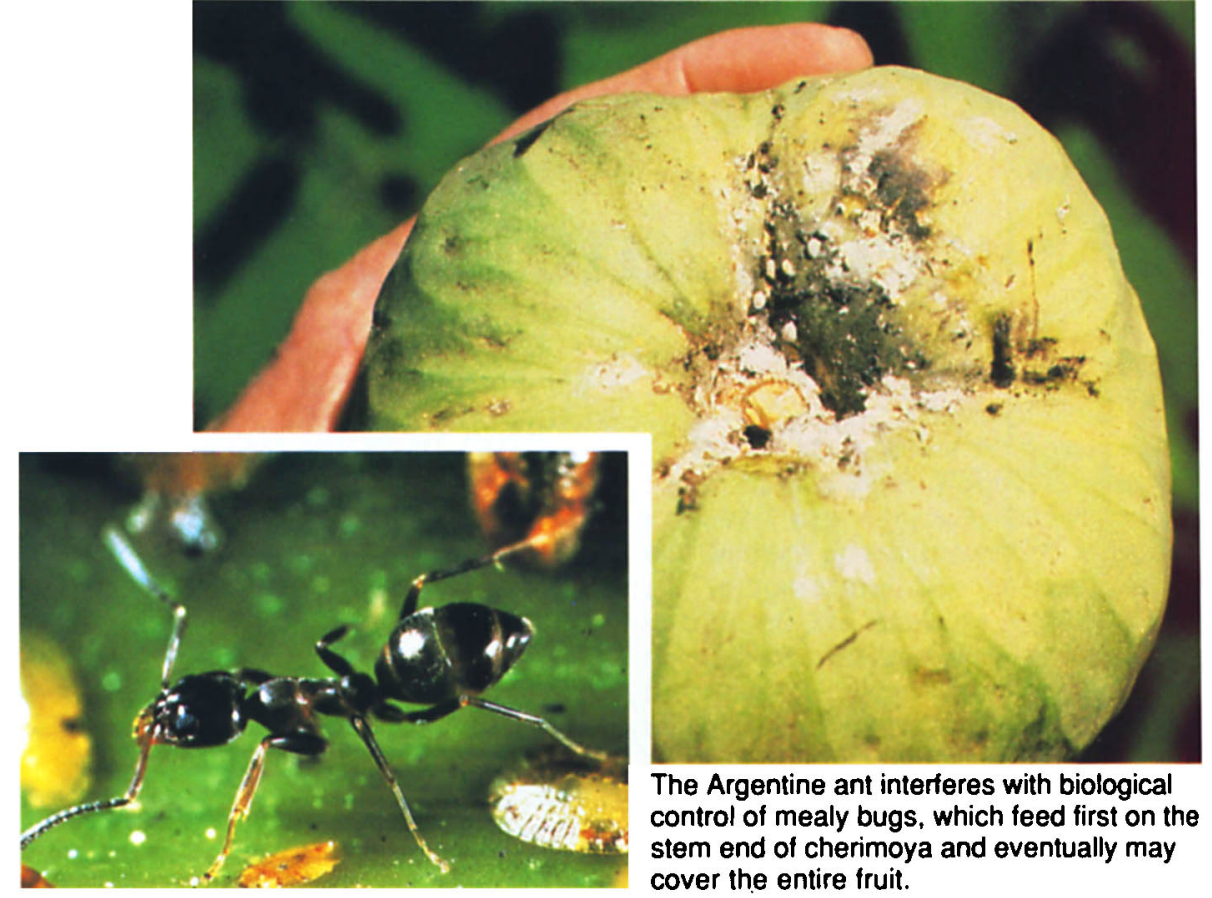

The Argentine ant interferes with biological control of mealy bugs, which feed first on the stem end of cherimoya and eventually may cover the entire fruit.

\section{Argentine ant management in cherimoyas}

Phil A. Phillips $\square$ Ronald S. Bekey

$T_{\text {he }}$ he hexagonally faceted fruit known as the cherimoya is native to the tropical mountain valleys of Ecuador and Peru. Spanish explorers introduced the fruit, Annona cherimola, into Spain, and from there it spread to other Mediterranean countries. It is now found in nearly all semitropical and subtropical climates worldwide.

The first known successful introduction into the United States occurred in California in 1871, when Judge R.B. Ord of Santa Barbara obtained some seed from Mexico. The state's first commercial planting was by Jacob Miller just before the turn of the century, near what is now the center of Hollywood. Commercial acreage in California today is about $\mathbf{2 0 0}$ acres, primarily in Santa Barbara, Ventura, and San Diego counties.

A similar fruit, the atimoya (an $A n$ nona hybrid) is grown in Florida. Small commercial cherimoya plantings also exist in Argentina, Spain, Egypt, South Africa, and Australia.

The cherimoya is actually a multiple fruit, similar to a pineapple in structure. Each hexagonal shield is a separate fruit that has fused with its neighbor, forming a heart-shaped ball. The flesh is butterywhite with an exotic pineapple-banana flavor. The trees are semideciduous, dropping their leaves in late April or early May in southern California. Blooming begins at the same time as the new leaves are produced, just after leaf drop, and may continue for several months. Fruits require about eight months to mature, so

\author{
George E. Goodall
}

the harvest period also extends for several months.

\section{Pests}

The cherimoya is relatively resistant to the common rootknot nemotode, Meloidogyne spp., and to avocado root rot, $P h y-$ tophthora cinnamomi. Oak root fungus, Armillarea mellea, and a fruit-spot disease that has not yet been identified have been reported in some orchards.

Cherimoyas grown in California have been free of some of the serious insect pests that occur elsewhere, including fruit flies, seed chalcids, and borers. Since 1945 , however, mealy bug infestations have been reported. As is true in other subtropical crops, such infestations can become economically devastating when biological control is disrupted by honeydew-seeking ants.

In Santa Barbara and Ventura counties, the Argentine ant, Iridomyrmex humilis, is the species most commonly involved. This ant, with its highly aggressive nature, displaces other less noxious ant species in the orchard and then interferes with biological control agents associated with honeydew-producing mealy bugs.

The long-tailed mealy bug, Pseudococcus adonidum, is the major insect threat to fruit quality. These mealy bugs usually attack the stem end of the fruit first and eventually cover the entire fruit. Infestations also may begin at contact points between fruits or between leaves and fruit. A sooty mold fungus, Cladosporium sp., 